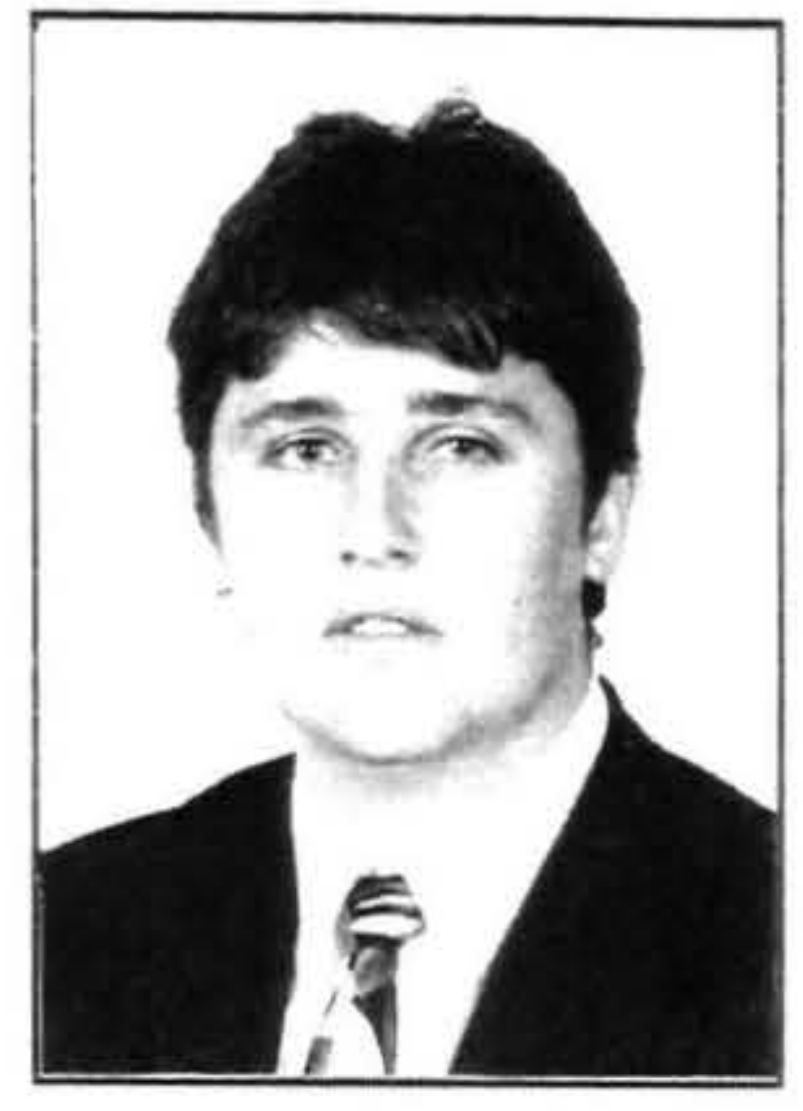

\title{
THE NEW ZEALAND LABOUR MARKET - AN UPDATE
}

\author{
Darren Gibbs \\ Labour Market Analysis Unit \\ Department of Labour
} \begin{abstract}
for the Prime Ministerial Taskforce on Employment.
Over the last 12-18 months, the New Zealand economy has moved from recovery to vigorous expansion. The economy grew by $1.3 \%$ (seasonally adjusted) in the June quarter 1994. This is the seventh consecutive quarter of positive growth. As Figure 1 shows, over the year to June 1994, economic activity was $6.1 \%$ higher than over the year to June 1993. This is the strongest annual growth rate recorded since 1984.
\end{abstract}

Abstract

The purpose of this paper is to briefly outline recent developments in the New Zealand labour market and some of the key features which characterise it. The material presented in this paper is an updated version of that originally prepared

As Figure 2 shows, economic growth continues to be broadly based. The general government services industry is the only group to have recorded a fall in output, with six of the remaining eight industry groups recording growth in excess of $5.0 \%$. The strongest increases were recorded in construction (16.6\%), Trade Restaurants, Hotels $(8.7 \%)$, Transport, Communications, \& Business/Personal Services $(6.9 \%)$, Manufacturing (5.8\%), and Agriculture(5.5\%). Figure 3 places New Zealand's growth rate in the context of that currently being achieved by our twelve largest trading partners. In addition to comparing well with our own economic history, New Zealand's current growth rate compares very favourably with the growth rates currently

\section{Figure 1. Production based real GDP growth}

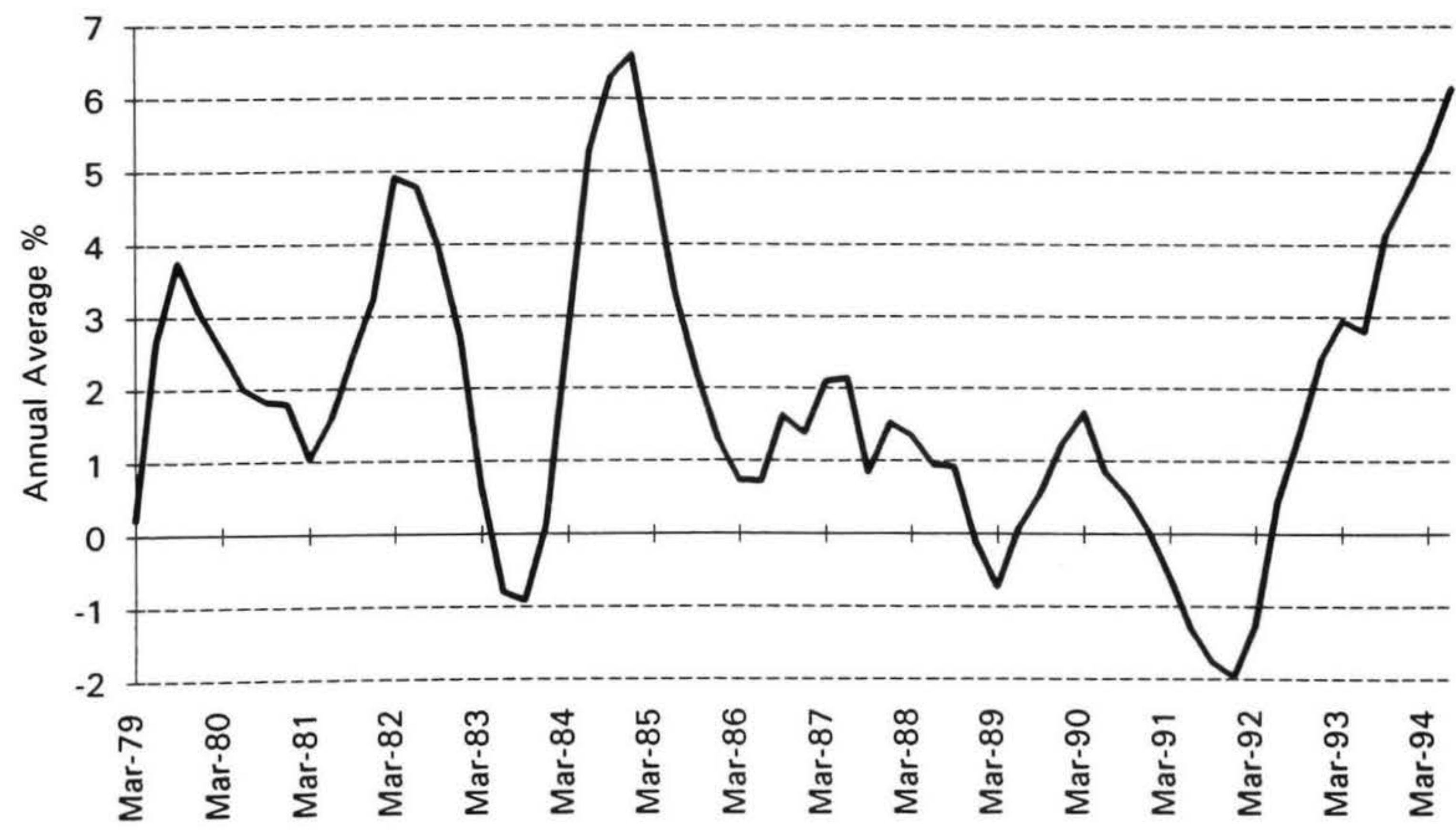


Figure 2. Real GDP growth rates by industry

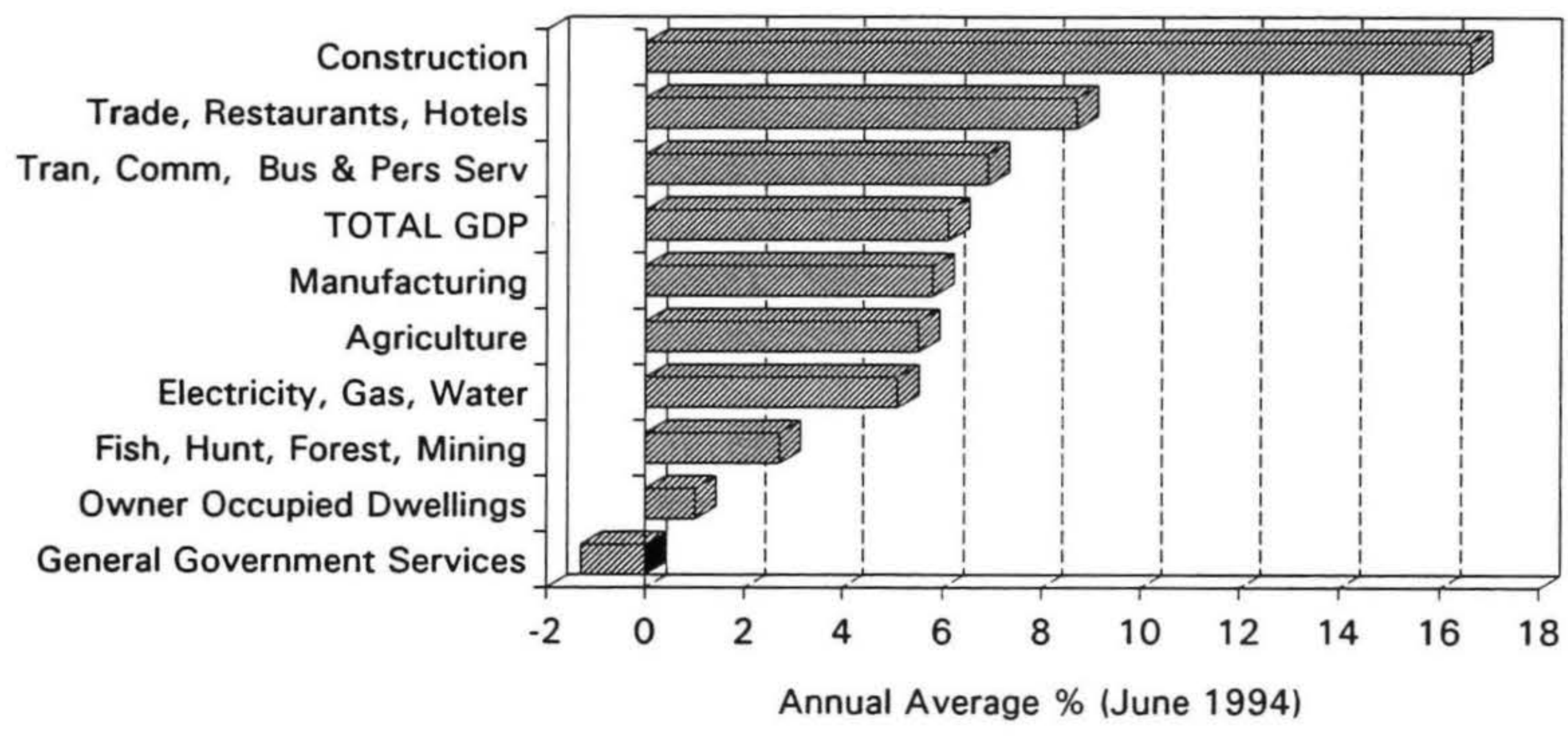

being achieved by our OECD trading partners, but is still somewhat lower than the rates of growth being achieved by our major Asian trading partners (with the exception of Hong Kong).

\section{Employment}

As one would expect, strong economic growth is translating into strong growth in employment and hours worked, and falling unemployment (see Figure 4).

According to the HouseholdLabour Force Survey (HLFS), the total number of employed persons increased by 63,600 in year to September 1994 (4.2\%). This followed growth of 41,800 in the year to September 1993 (2.9\%). The employer-based Quarterly Employment Survey (QES) tells a similar story with the number of filled jobs increasing by $72,000(5.5 \%)$ in the year to August 1994 , the

Figure 3. New Zealand's growth rate compared with 12 largest trading partners

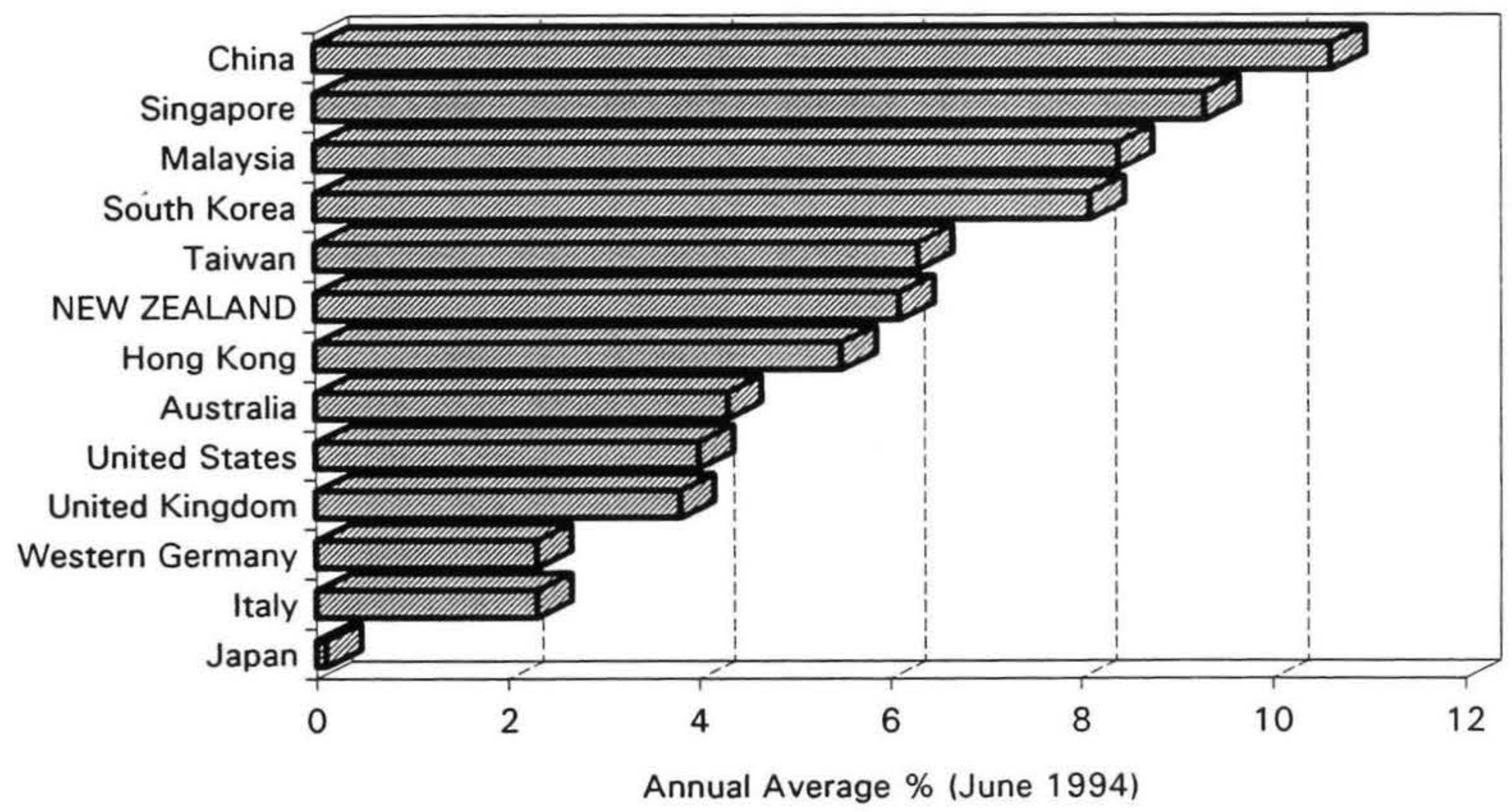


Figure 4. Real GDP growth and employment growth

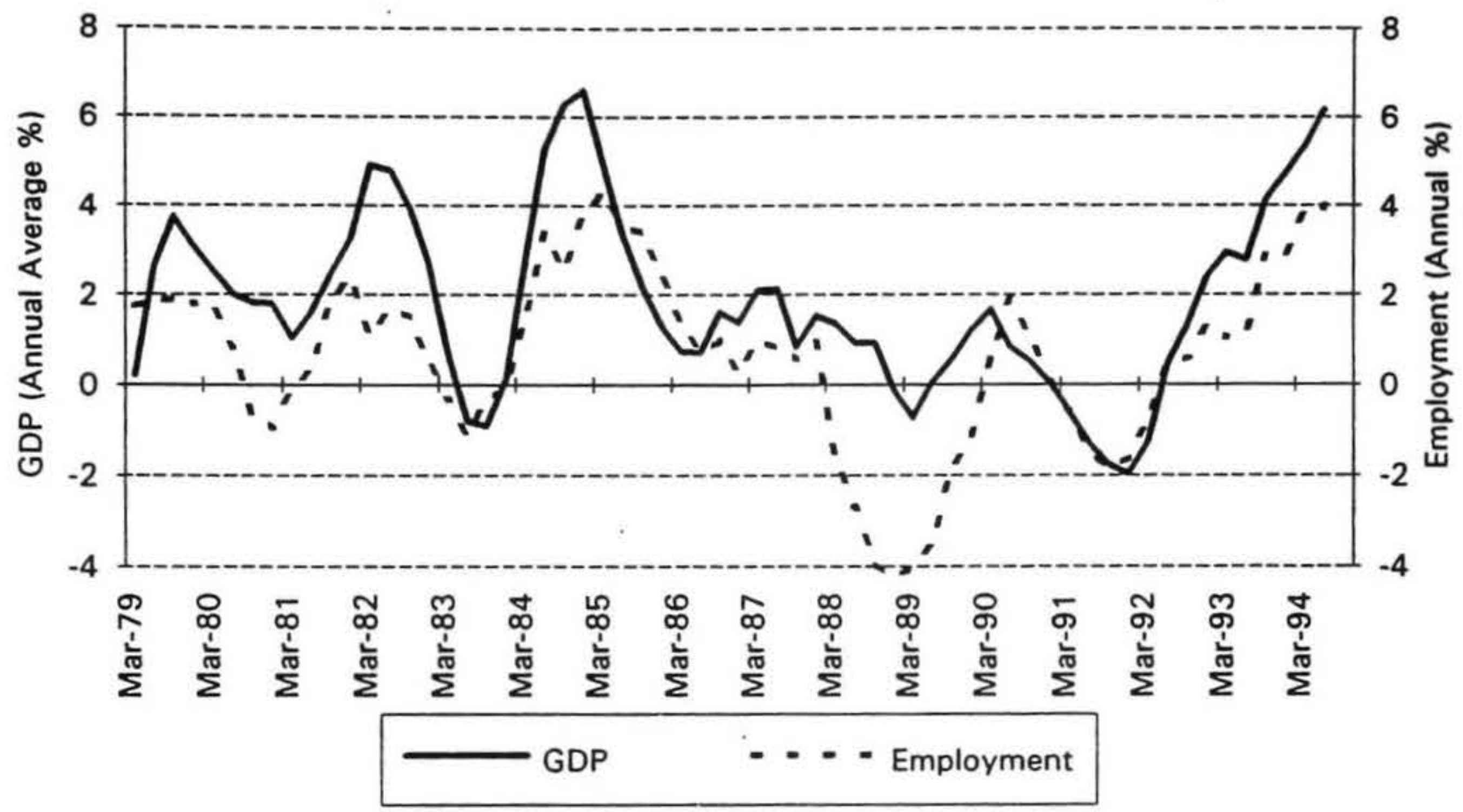

slightly stronger increase perhaps reflecting a greater propensity for people to hold more than one part-time job. The number of hours worked as measured by the HLFS increased by $4.4 \%$ in the year to September 1994.

Focusing on the HLFS, of the jobs created over the last year, 42,900 (or $68 \%$ ) were fulltime (i.e. greater than 30 hours per week). Male employment increased by 35,700 ( $77 \%$ were fulltime), while female employment increased by 27,700 ( $56 \%$ were fulltime).

The proportion of the labour force working non-standard working hours has increased. For example, the proportion of the employees working in excess of 50 hours per week is now $20.4 \%$ compared with $16.3 \%$ in September 1986 , while the proportion employed for between 1 and 20 hours is now around $14.5 \%$ compared with around $11.5 \%$ in September 1986 (although this latter trend appears to have flattened off over the last couple of years).

Figure 5 illustrates HLFS employment growth by industry over the year to September 1994. As suggested by the GDP data, the strongest employment growth has occurred in the construction, manufacturing, and wholesale and retail trade groups (all have grown by in excess of $10 \%$ ). In absolute terms, manufacturing accounts for the strongest

Figure 5. Employment growth by industry (Year to September 1994)

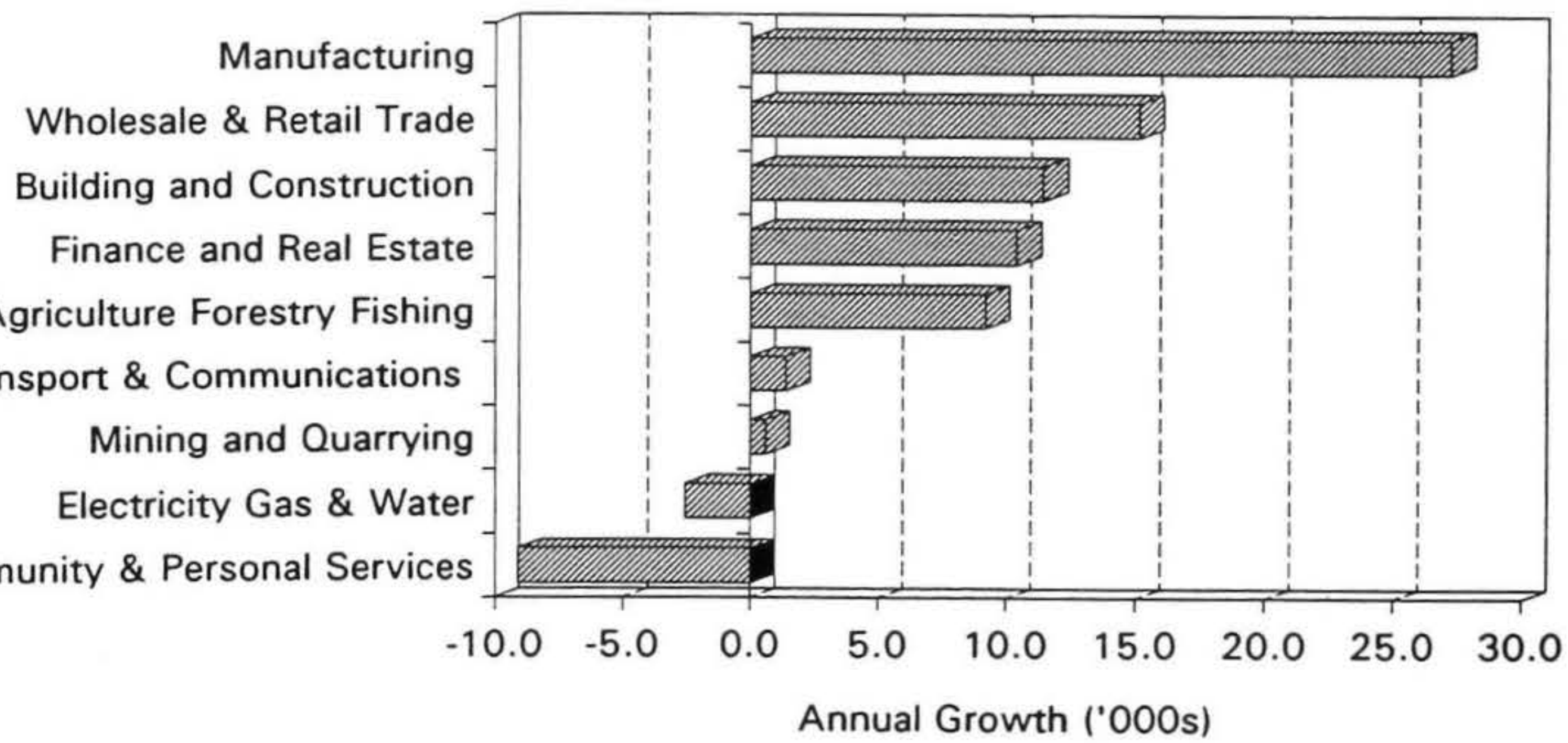


Figure 6. Employment growth by occupation (Year to September 1994)

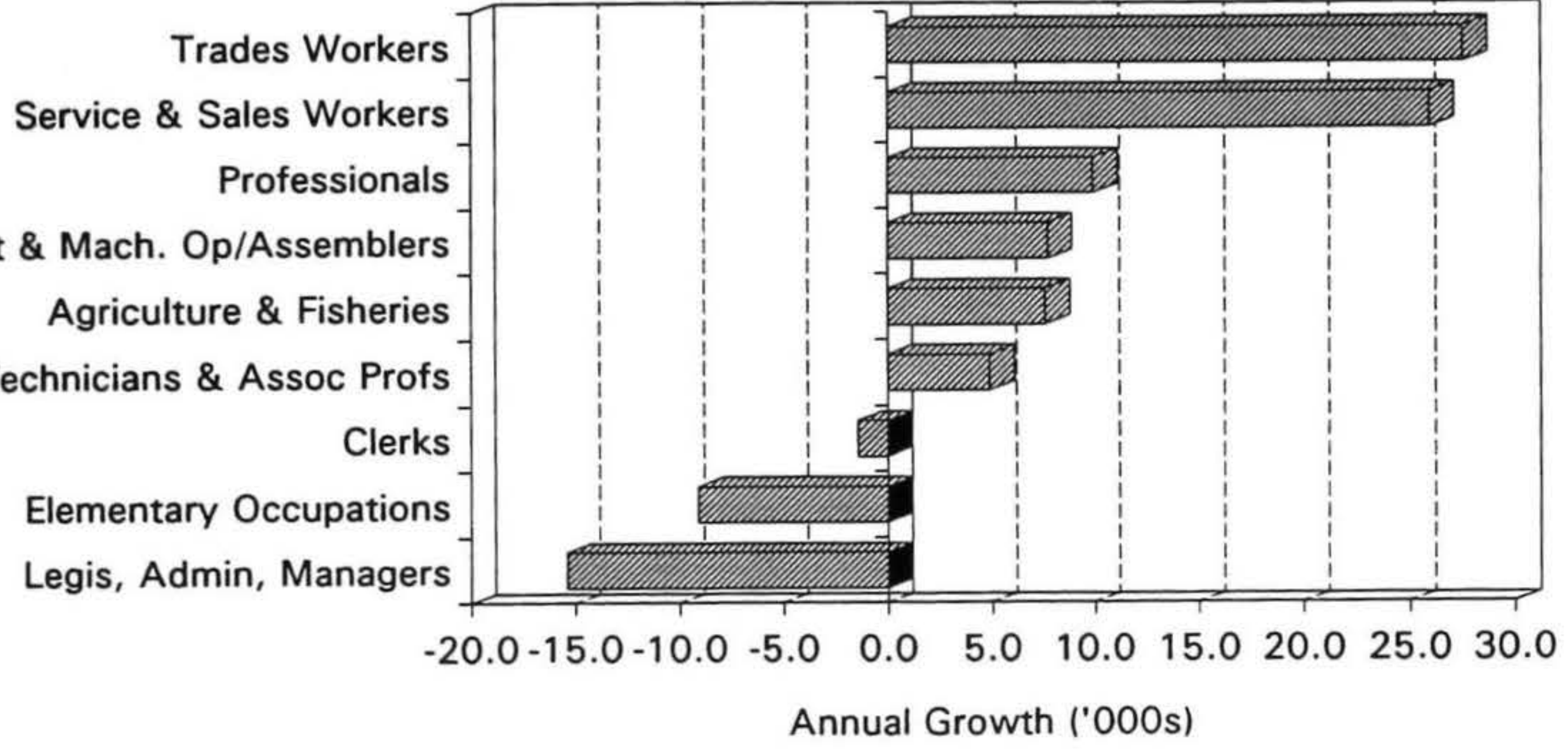

growth $(27,200)$, while wholesale and retail trade $(15,100)$, construction $(11,400)$, business and financial services $(10,400)$, and agriculture $(9,200)$ also make strong contributions.

As figure 6 shows, the occupation breakdown of job growth reflects the industry data, with the trades worker and service and sales worker categories recording the largest increases. However, at the same time, large declines have also occurred in the elementary (mainly labouring) and managerial categories.

\section{Unemployment}

Historically there has been a strong positive link between employment growth and changes in labour force participa- tion. In the case where employment prospects are improving, this relationship reflects both the direct impact of newly employed people entering the labour force, and an indirect impact, whereby non-participants upon observing the improvement in labour market conditions, are encouraged to begin searching for work.

As figure 7 shows, this relationship appears to have held over the last two years, with the pick-up in employment growth translating into an increase in labour force participation. However, looking at the aggregate participation rate alone can be somewhat misleading. This is because the recent increase in participation has been dominated by two particular cohorts. First, the participation rate of those persons aged 60-64 years has risen sharply from around $25 \%$ in September 1992 to 33\% in September 94, presum-

\section{Figure 7. Employment growth and the participation rate}

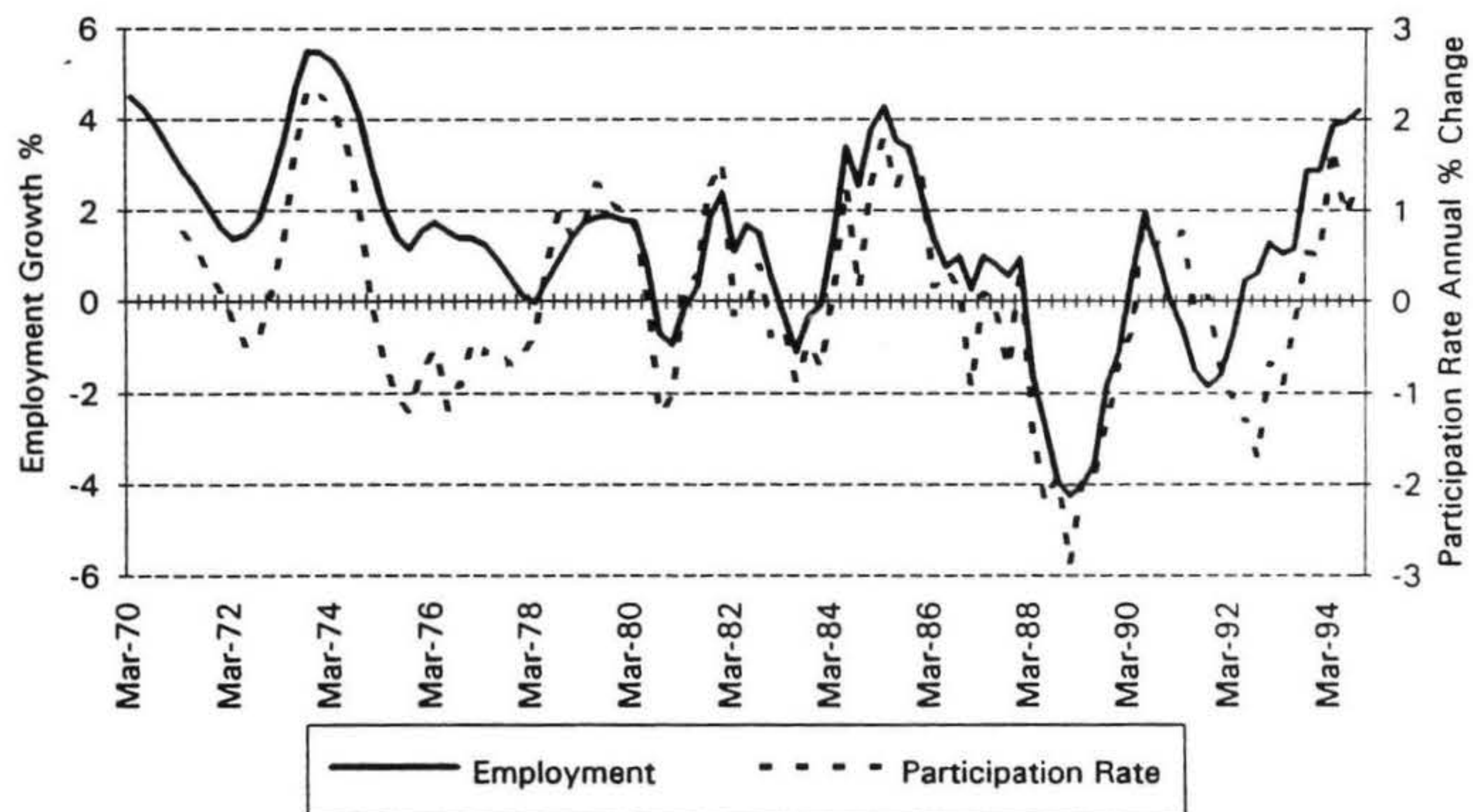




\section{Figure 8. Participation Rates}

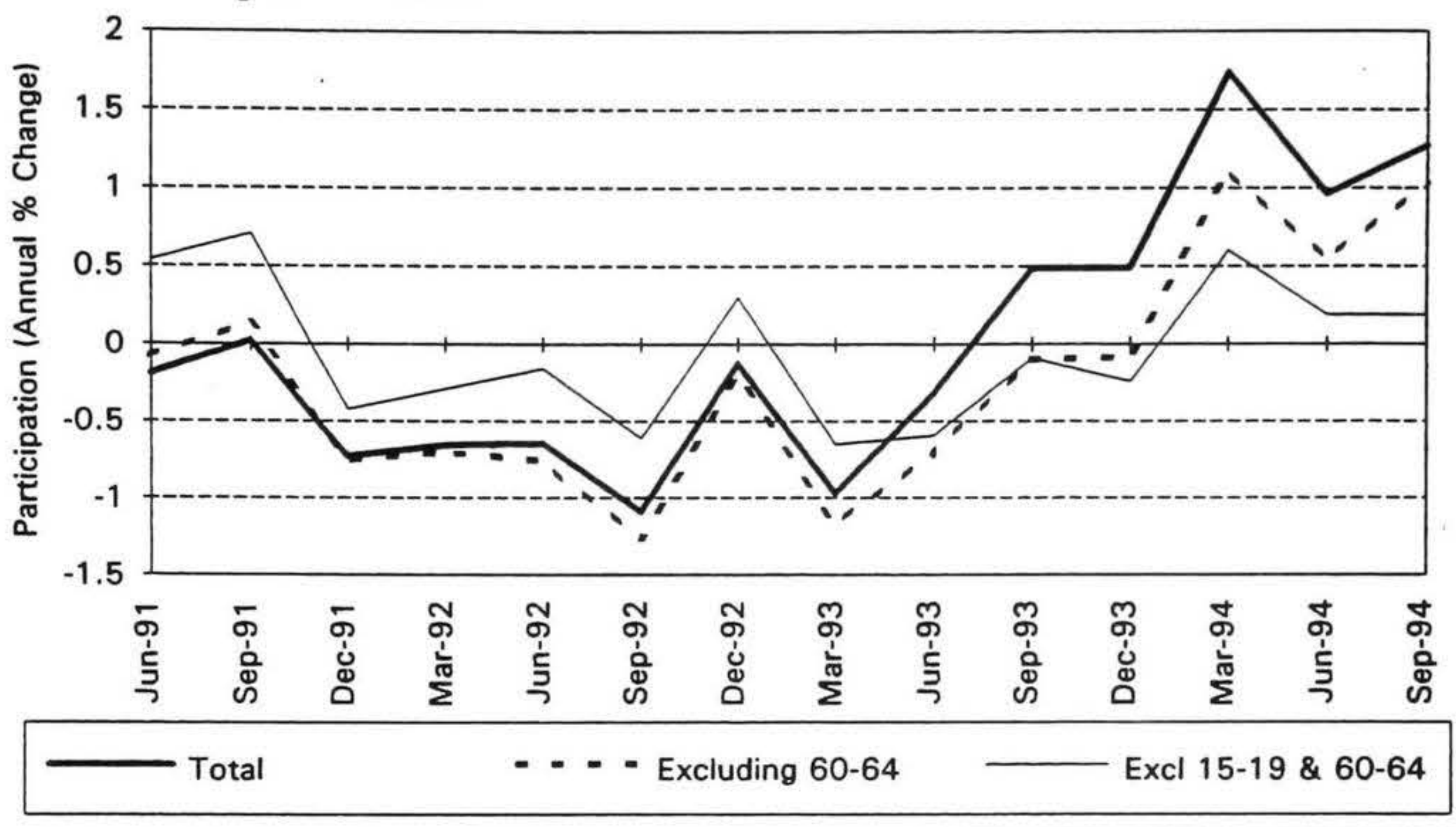

ably in response to changes in the age of eligibility for national superannuation. Second, the participation rate of those persons aged 15-19, after trending down from around $65 \%$ in 1986 to around $50 \%$ in 1993, has also begun to rise steadily, particularly in the September 1994 quarter during which it increased sharply from $51.5 \%$ to $54.5 \%$ in seasonally adjusted terms.

As figure 8 illustrates, the participation rate response of the core working age participation to improving employment conditions has been almost nonexistent over the last two years, that is when one excludes the behaviour of these atypical cohorts from the aggregate figures.

Despite a sharp increase in labour supply due to natural change, positive net migration, and increased labour force participation, both the level and rate of unemployment have fallen over the last 12 months.

As figure 9 shows, this observation holds true for a variety of definitions of unemployment, from those used in the HLFS (the Official Unemployed and Jobless series) to data collected by the Department of Labour (registered unemployed) and the Department of Social Welfare (numbers on the Unemployment Benefit). For example, over the year to September 1994, the number of people officially unemployed has fallen by around 21,000 , the number registered has fallen by around 27,000 , while the number on unemployment benefits has fallen by around 17,000.

In seasonally adjusted terms, the HLFS official unemployment rate has fallen from a peak of $10.9 \%$ in September

Figure 9. Unemployment (seasonally adjusted)

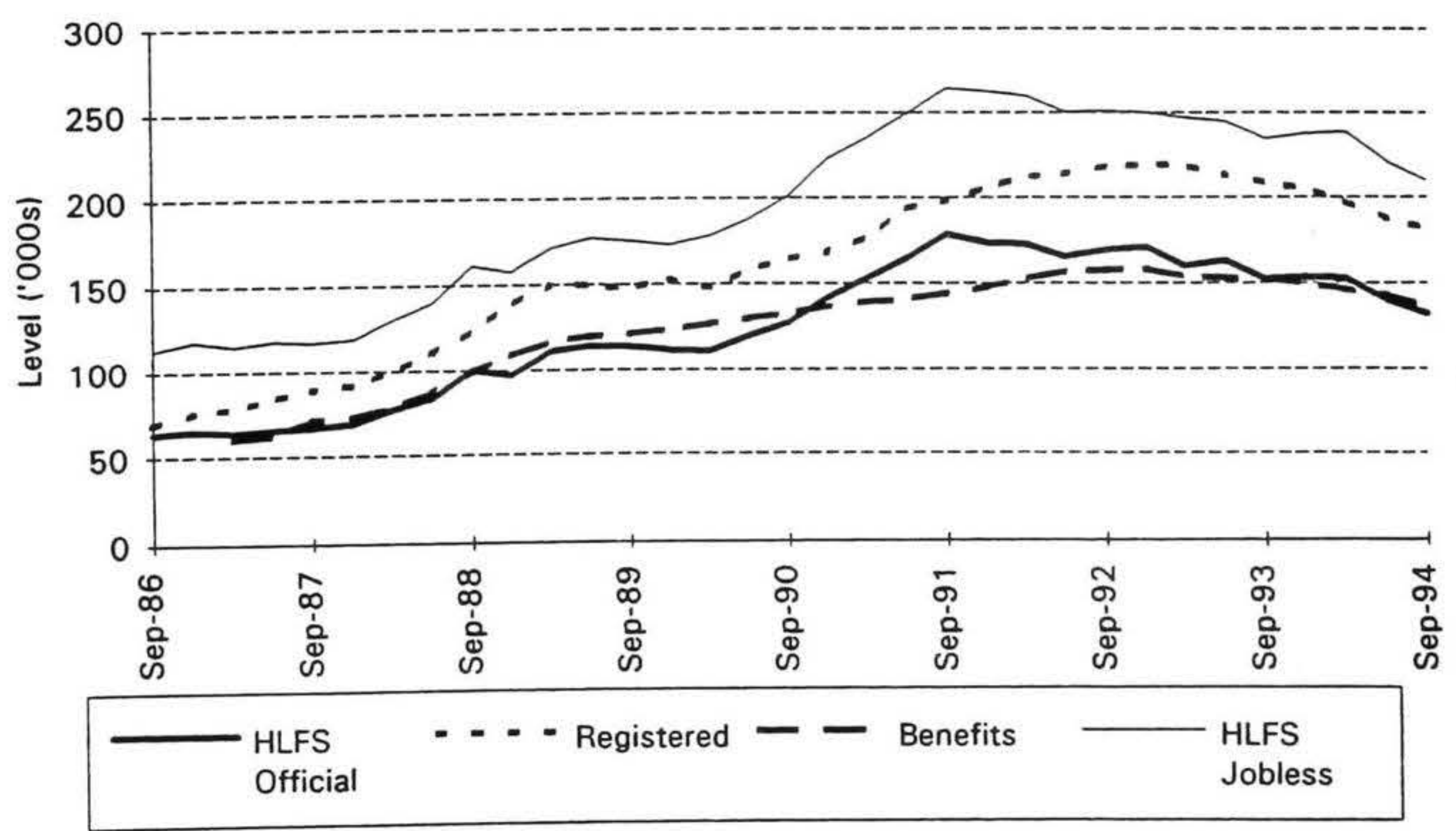


Figure 10. HLFS official unemployment rate (Seasonally adjusted)

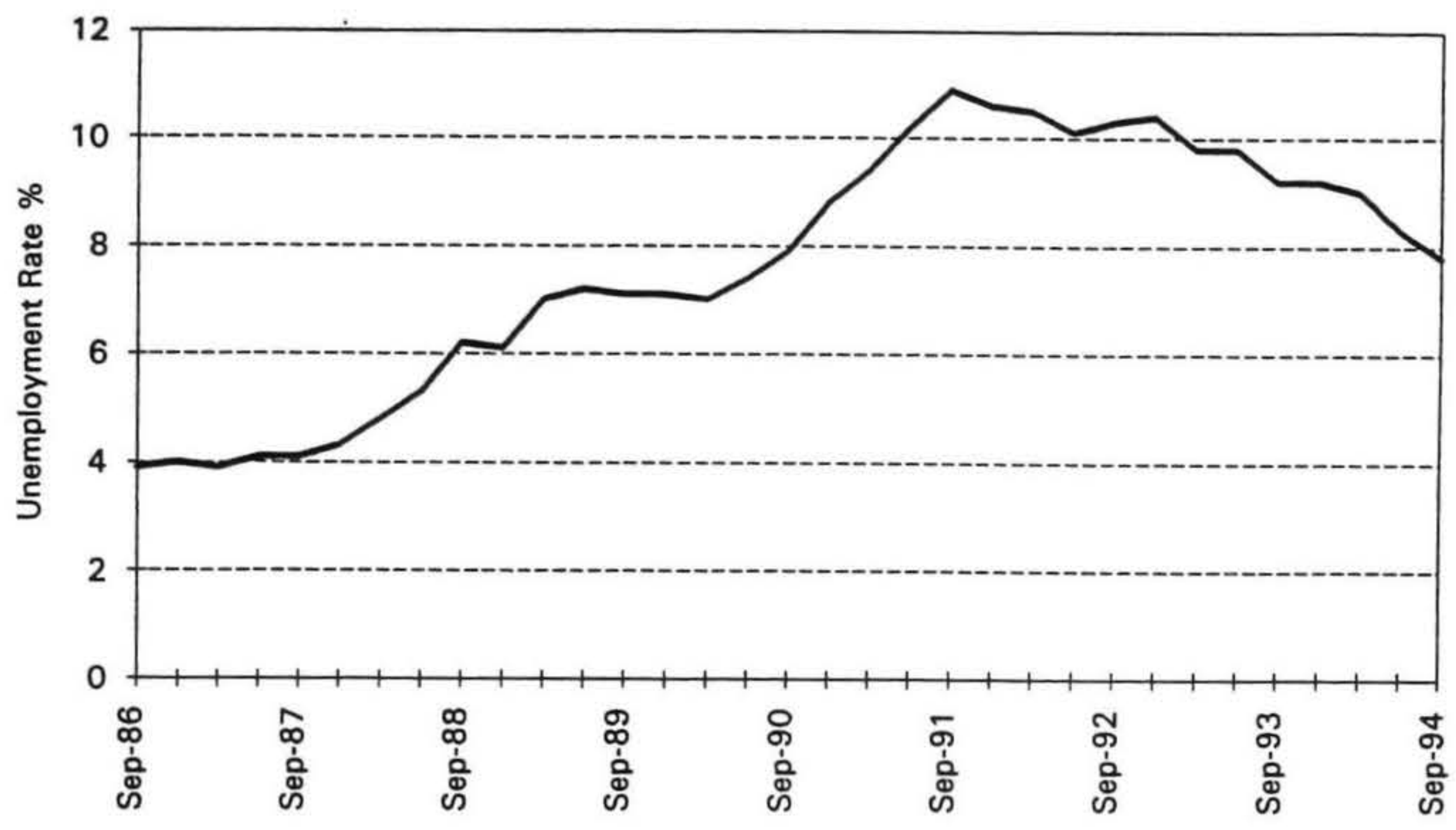

1991 to $7.8 \%$ in September 1994.

As table 1 shows, the fall in unemployment rates has not been restricted to any one sector of the community. Rather, people of different gender, ages, ethnicity, locality, and educational attainment, all appear to be benefiting from the growth in employment. However, importantly, as the table also shows, there remains a wide dispersion in the incidence of unemployment.

For example, the incidence of unemployment for males is slightly greater than for females; the incidence for those persons aged 15-19 is around 2.5 times greater than for those persons in the core working age groups; the incidence for Maori is around four times greater than for Europeans, as is the incidence for Pacific Islands people. This source of disadvantage is even greater when one allows for the relatively low rates of labour force participation of Maori and Pacific Islands people. The incidence for Maori is in excess of five times greater than Europeans, rather than four times, when one adjusts for lower Maori labour force participation. Maori labour force participation was around the same level as that of Europeans in the mid 1980s. Labour force participation rates also vary regionally: the incidence among persons living in Northland is around twice that of persons living in Canterbury, or Otago/Southland. Variations are also apparent by qualifications: the incidence among persons with no qualifications is around three times greater than among those persons with post-school and school qualifications.

The uneven burden of unemployment can also be seen by analysing the concentration of unemployment across indi-

Figure 11. Distribution of total person-weeks registered unemployment (June 1990 - June 1994)

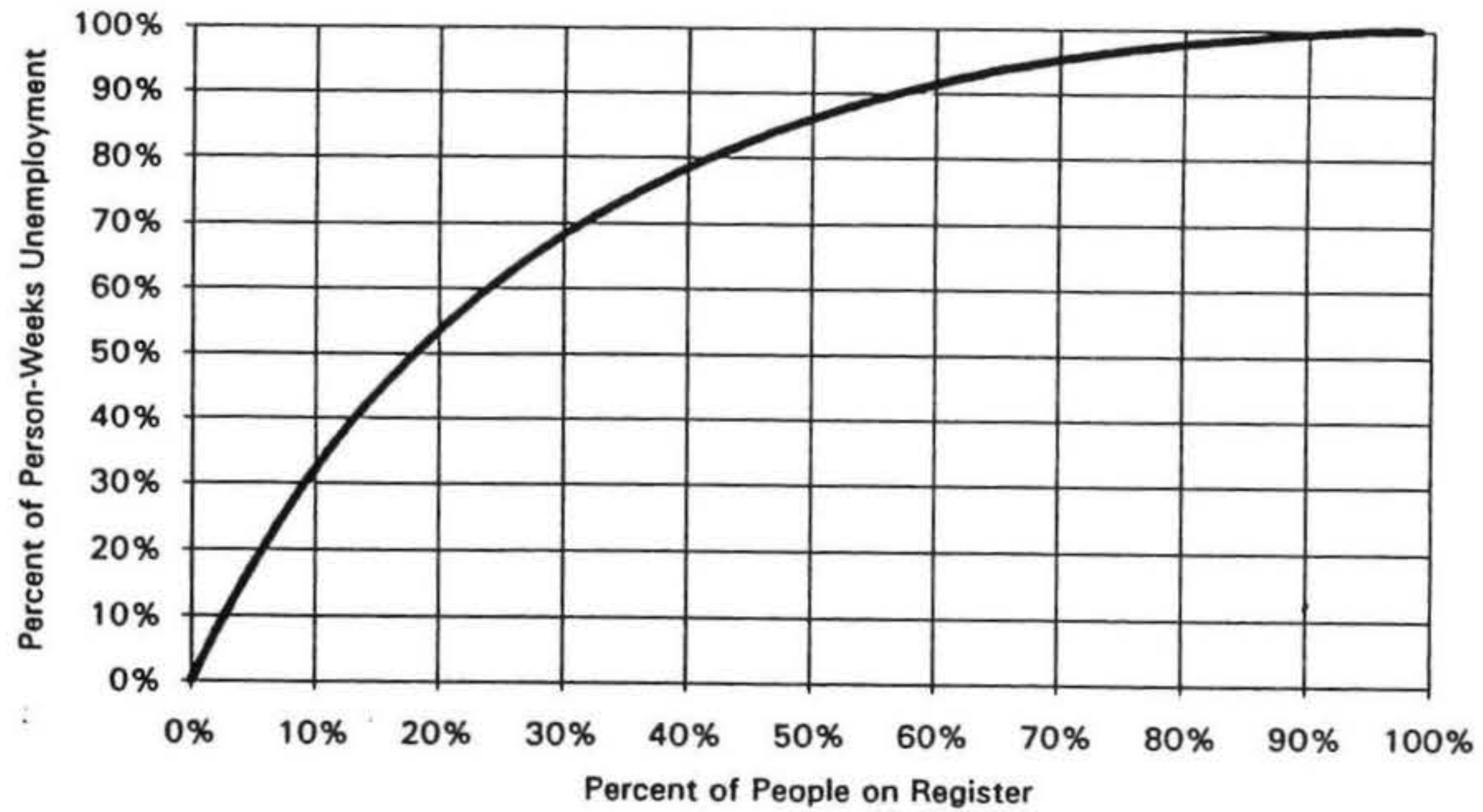




\begin{tabular}{lrrr}
\hline & Sep 92 & Sep 93 & Sep 94 \\
\hline Aggregate Rate & 10.0 & 9.0 & 7.5 \\
Males & 10.9 & 9.6 & 8.1 \\
Females & 8.9 & 8.2 & 6.8 \\
Age 15-19 & & & \\
Age 20-24 & 21.8 & 18.9 & 16.0 \\
Age 25-55 & 15.4 & 12.9 & 11.2 \\
Age 55+ & 8.2 & 7.7 & 6.4 \\
& 5.7 & 4.8 & 3.9 \\
European/Pakeha & & & \\
NZ Maori & 7.8 & 6.7 & 5.4 \\
Pacific Islands & 25.2 & 22.7 & 20.8 \\
Northland & 25.2 & 25.2 & 22.2 \\
Auckland & & & 13.6 \\
Taranaki/Manawatu & 11.6 & 14.4 & 7.3 \\
Wellington & 10.7 & 9.6 & 8.6 \\
Canterbury & 11.0 & 9.6 & 7.9 \\
Otago/Southland & 9.3 & 8.7 & 5.9 \\
& 8.9 & 6.5 & 6.5 \\
No Qualifications & 8.4 & 7.9 & 12.9 \\
School Qualifications & & & 6.9 \\
Post School \& School & 16.1 & 14.7 & 4.0 \\
\hline
\end{tabular}

Source: Statistics New Zealand

viduals (see Figure 11). This figure was constructed by adding up all the person-weeks of registered unemployment experienced over the four years to June 1994 - a total of 42.7 million person weeks. These were distributed across 750,816 different persons who had been registered with the New Zealand Employment Service (NZES) for at least some time over those four years.

The burden of unemployment is shared very unevenly. For example, $10 \%$ of the people unemployed accounted for one third of all person-weeks of registered unemployment, while $17.5 \%$ accounted for around half of all personweeks. On average, this latter group had been unemployed for 155 of the 209 weeks in that period, distributed over an average of 2.3 spells of unemployment per person.

\section{Long-Term Unemployment}

Figure 12 illustrates the duration profile of the registered unemployed as of the end of October 1994. The distribution is extremely skewed with approximately two-thirds of the registered unemployed having registered since the beginning of 1994 , while $81 \%$ have registered since the beginning of 1993. At the other end of the distribution, five people have been registered as unemployed continuously since 1983. The important point to note here is the large number of people at the short duration end of the distribution, and the long tail of the other end. Much of the growth in unemployment in recent years has been due to the increase in the proportion of long term unemployed (see
Figure 13).

This relationship has also been observed in many other OECD countries, particularly those in Europe such as France, Britain, Sweden and Italy, but also in Canada and Australia. More recently, however, while the aggregate unemployment rate has fallen, the incidence of long-term unemployment has hardly changed. Nevertheless, as figure 14 shows, the number of registered long-term unemployed is falling.

As one might expect with economic growth, the number of people with relatively shorter durations was the first to fall. For example, the number of people unemployed for between 26-51 weeks has been falling since the beginning of 1992. By contrast, the number unemployed for between 12 years only began to fall in early 1993 , while it is only since the beginning of 1994 that the number of people unemployed for over 2 years has fallen.

\section{The dynamic labour market}

Although most people are familiar with the magnitude of the stock of unemployed, few are as familiar with the magnitude of the underlying flows. Table 2 is constructed from gross flow data obtained from the HLFS. Statistics New Zealand is able to match around $75 \%$ of the respondents between consecutive surveys because of the rotation pattern underlying the survey's sample design. As table 2 shows, the labour market is far from static. The net 
Figure 12. Duration profile of registered unemployed (October 1994)

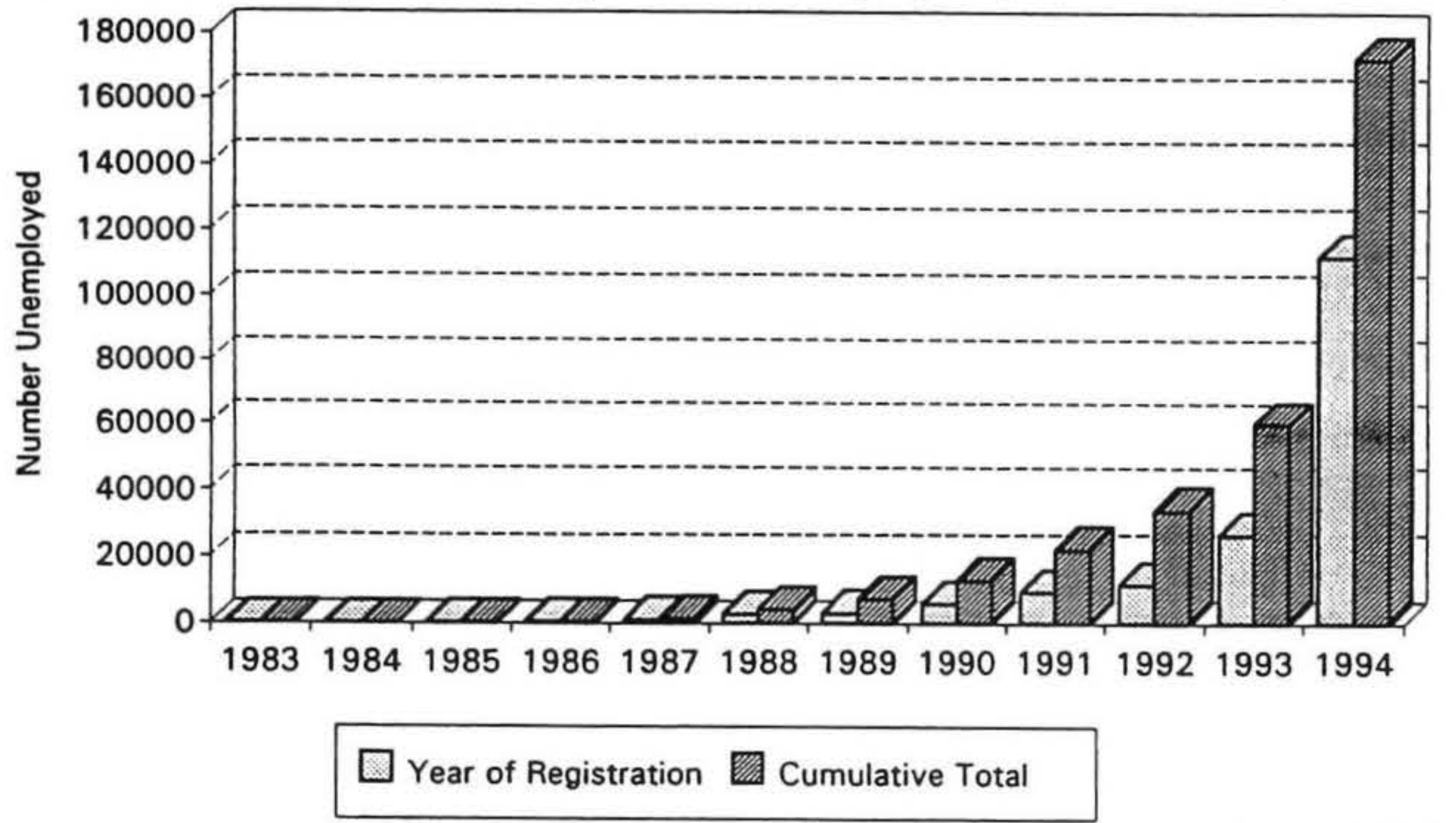

movements are not necessarily great, but the gross flows are. For example, for the matched samples, over the year to September 1994, the average net quarterly growth in the labour force was around 1,800 people. However, this small net change was generated by an inflow of 70,200 people who entered the labour force $(44,500$ going directly into employment, and 25,700 into the ranks of the unemployed), and an outflow of 68,400 people who left the labour force $(43,900$ having been previously employed, and 24,500 previously unemployed).

The table also reveals a number of other interesting features. For example, of the average 89,300 persons unemployed in a given quarter, only 40,500 persons were still unemployed in the following quarter, with 24,300 persons having found work and 24,500 persons having moved out of the labour force. Furthermore, around two-thirds of the additional jobs being created in any given quarter are taken by people who were not in the labour force during the previous quarter, with previously unemployed people obtaining the remaining third.

An alternative way of presenting this data is to look at transition probabilities. These measure the probability of a sampled individual moving from one labour market status to another in consecutive quarters. As figure 15 shows, the probability of remaining unemployed for two consecutive quarters has begun to fall over the last 12-18 months while the probability of moving from the state of unemployment to employment has very gradually begun to rise.

The Department of Labour's unemployment register can

Figure 13. Proportion long-term unemployed and unemployment rate (September quarters)

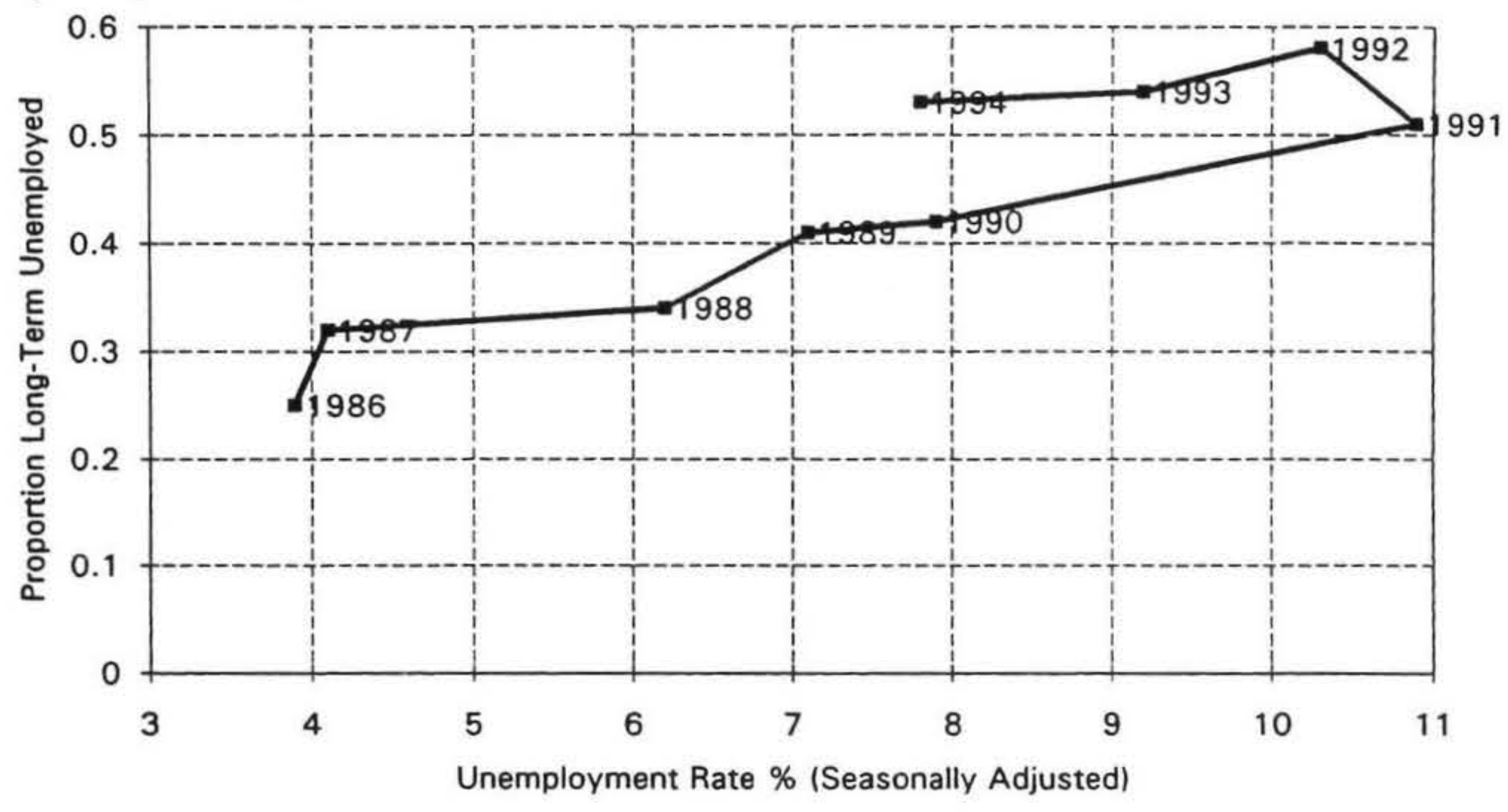




\section{Figure 14. Registered long-term unemployment by duration}

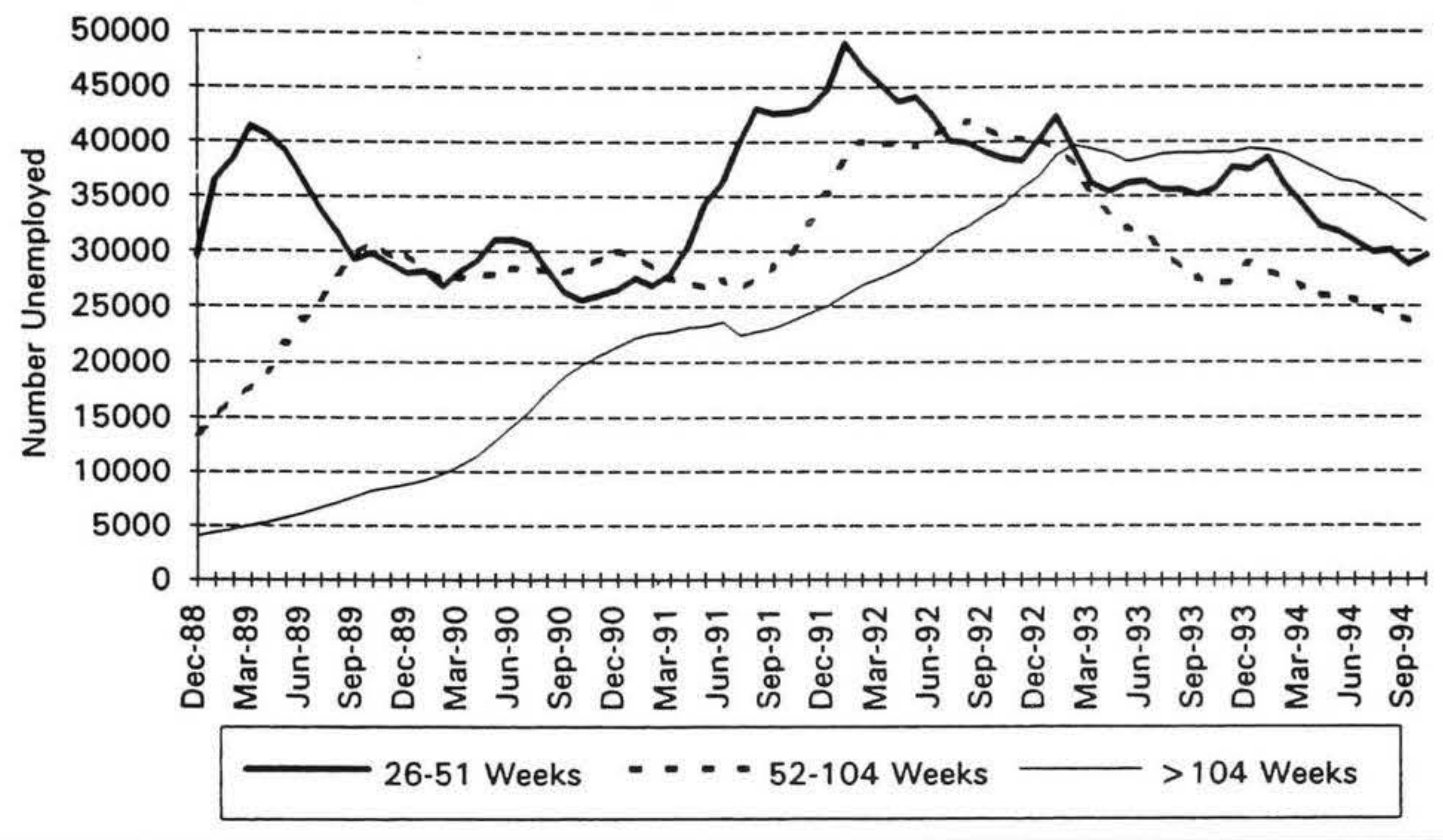

also be used to examine labour market dynamics. Figure 16 illustrates the gross flows on to and off the register for each of the last four years.

Over the four years to June 1994 , around 290,000 people on average, flowed onto and off the register each year (these numbers include those who may have registered or left the register more than once). In 1994, the net flows turned strongly positive, and this is reflected in the fact that the average stock on the unemployment register fell in 1994, after rising over each of the previous two years.

With increasing employment growth, one would expect gross outflows to increase, as has been the case. However, for similar reasons, one might also have expected the level of gross inflows to fall, but this has not happened. The gross inflow onto the unemployment register has remained relatively constant over the last four years, while the level of gross outflows has consistently increased.

There are several possible explanations for this. These include the return to the labour force of those previously not participating, increased use of short-term contracts (which would act to raise both inflow and outflow numbers), or possibly increased willingness by potential employees to make use of the NZES service.

\section{The outlook for employment and unemployment}

Consensus forecasts collated by the New Zealand Institute of Economic Research (NZIER) suggests that the outlook for employment and unemployment is relatively positive (see Figures 17 and 18). In the September 1994 survey, economic growth of $4.5 \%$ was expected over 1994/95 followed by $3.5 \%$ growth in the following two years. In turn, continued economic growth was expected to lead to employment growth of around three percent in the year to March 1995, and just over two percent in the following two years. Nevertheless, the unemployment rate was expected to fall only gradually, reaching $7.3 \%$ by March 1997 , although the range of unemployment rate forecasts spans $6.0-8.5 \%$ for that year.

These forecasts were collated before the release of the better than expected September HLFS figures (recall that

\section{Table 2. Gross flows average for year to September 1994 (HLFS)}

\section{Status in Quarter $\mathrm{t}+1$}

Status In Quarter t

Employed Unemployed Not in Labour Force Total

\begin{tabular}{lrrrr}
\hline Employed & 926.0 & 16.7 & 43.9 & 986.6 \\
Unemployed & 24.3 & 40.5 & 24.5 & 89.3 \\
Not in Labour Force & 44.5 & 25.7 & 558.2 & 628.3 \\
Total & 994.8 & 82.9 & 626.5 & 1704.1 \\
\hline
\end{tabular}

Source: Statistics New Zealand 
Figure 15. Transition probabilities (Seasonally adjusted)

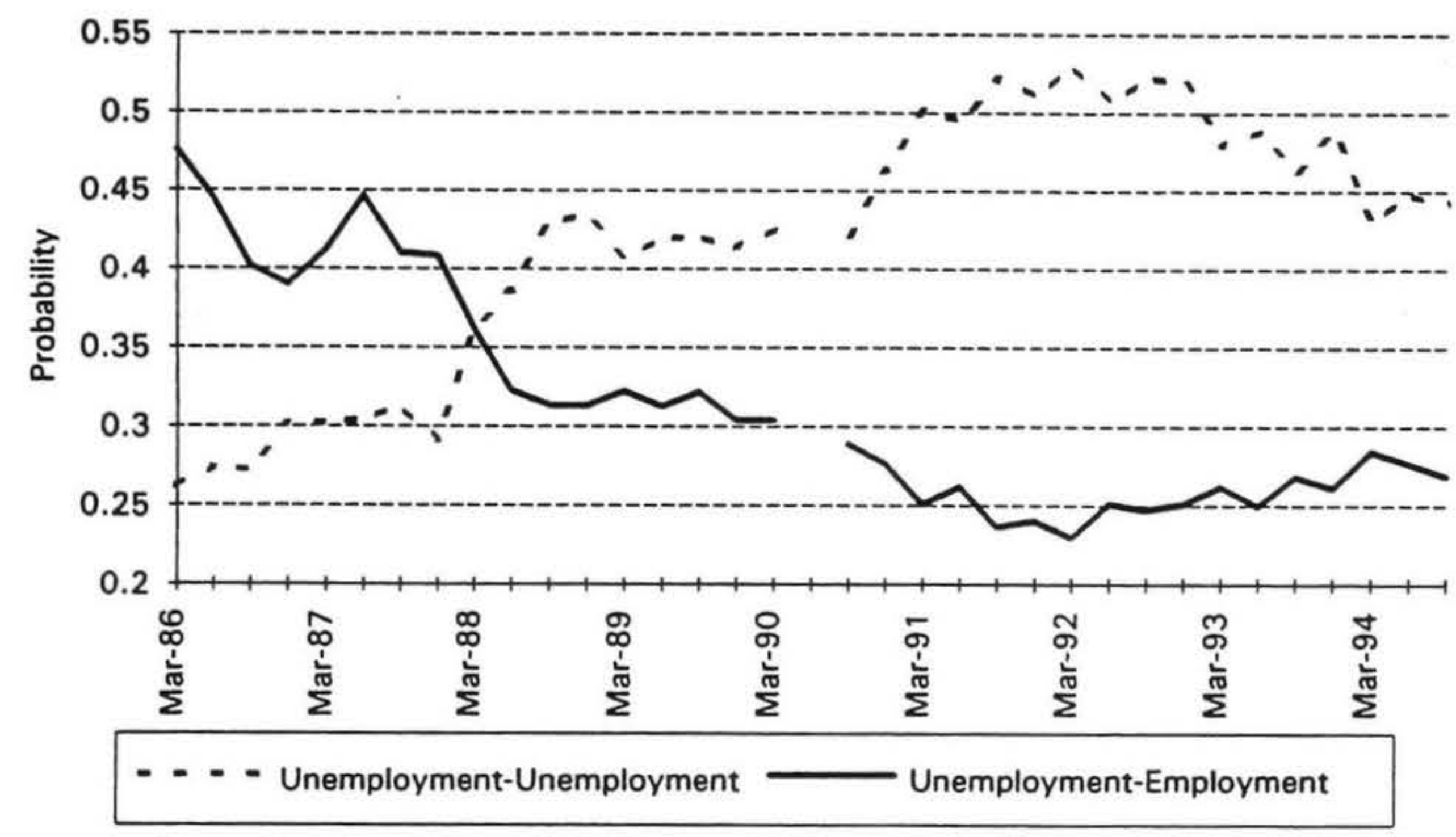

Figure 16. Gross flows and stock from unemployment register (Year to June)

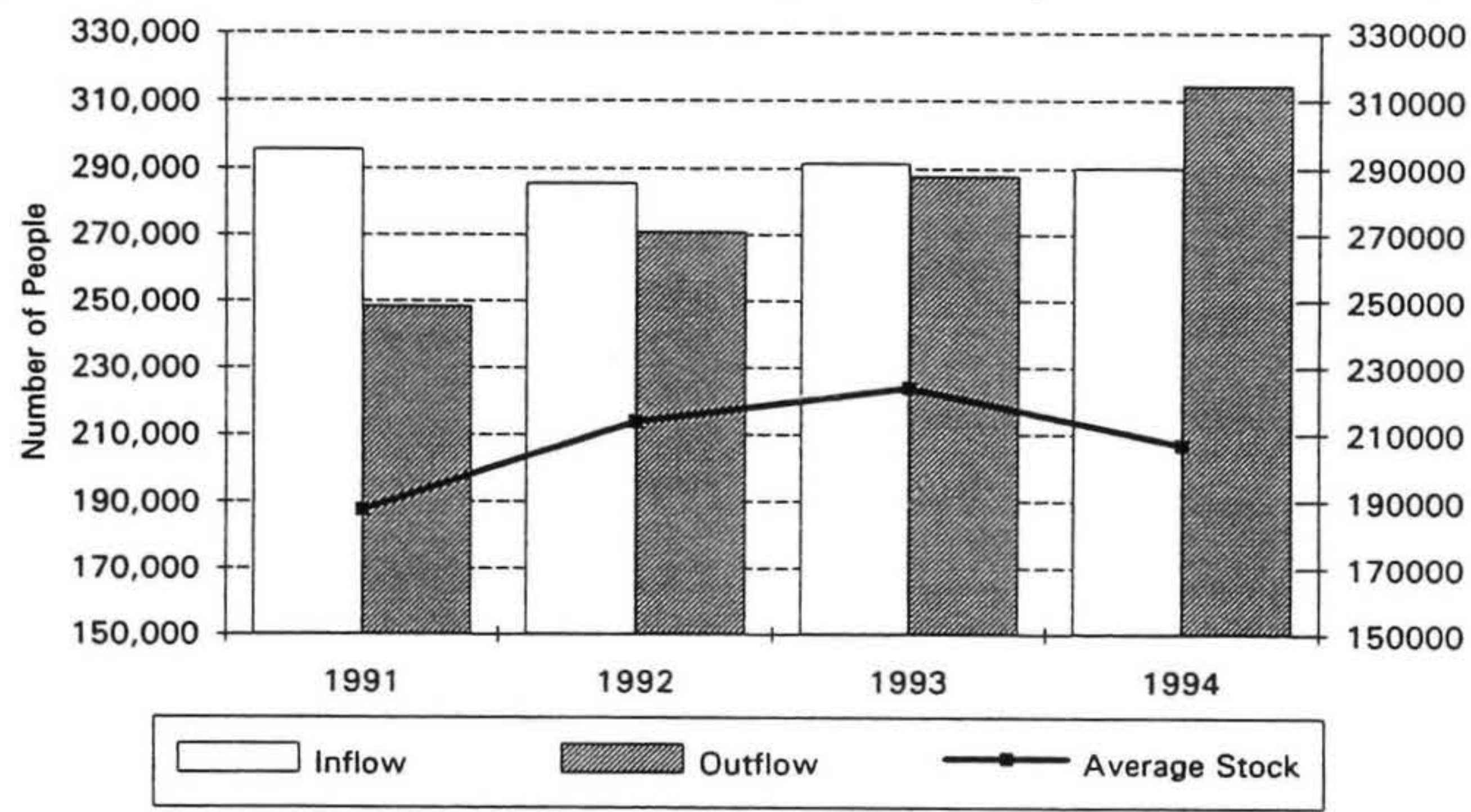

Figure 17. NZIER September 1994 consensus employment forecasts

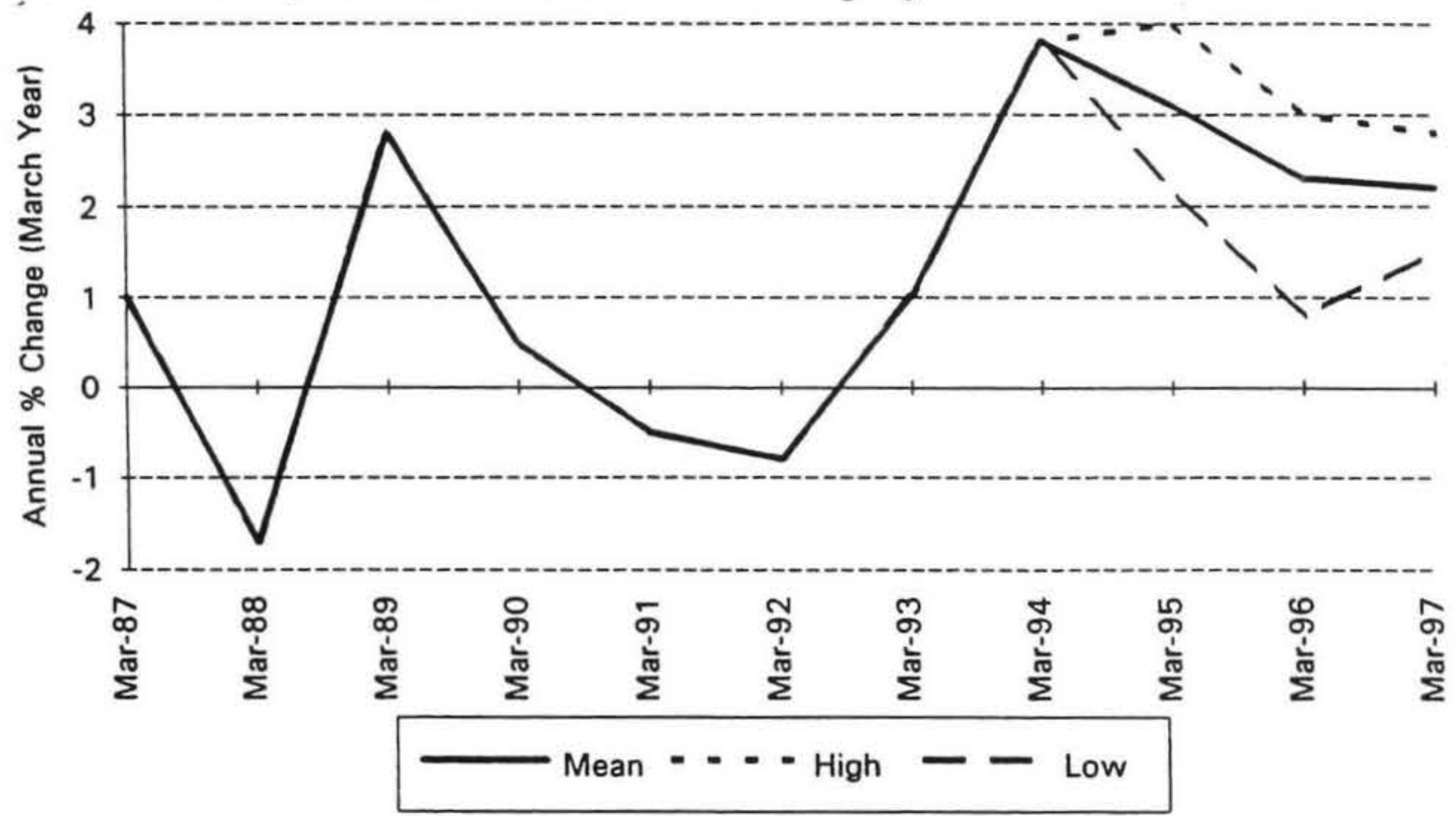


Figure 18. NZIER September 1994 consensus unemployment forecasts

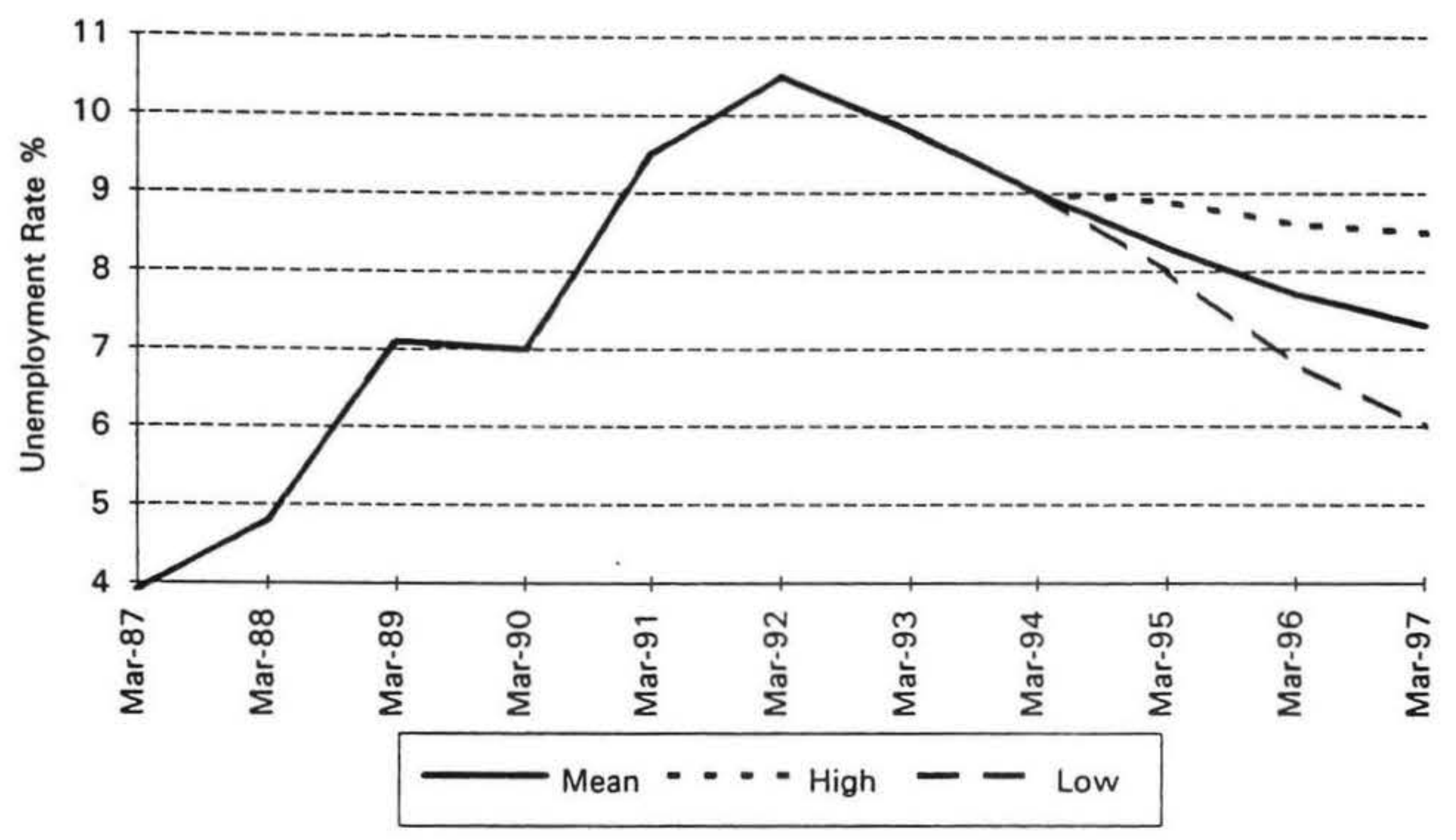

the unemployment rate has already fallen to $7.8 \%$ ). This is likely to lead forecasters to revise down their unemployment forecasts over the next six months. A key judgement that needs to be made is what is the level of 'cyclical' unemployment remaining in the economy i.e. what is currently the 'natural' or 'equilibrium' rate of unemployment beyond which further declines in unemployment inevitably generate inflation.

In New Zealand, there is little empirical work from which to answer the question. Nevertheless, given the low levels of unemployment now beginning to be seen in some sections of the labour force - particularly among Europeans and those with qualifications, it is clear that the scope for continued substantial declines in aggregate unemployment will heavily depend on the conduct of appropriate policies to reduce the excessive burden of unemployment amongst youth, Maori, Pacific Island's people, and the long-term unemployed more generally.

\section{Conclusion}

The last two years has seen very strong growth in economic activity, significant employment growth across a wide range of industries and occupations, and a sharp decline in unemployment. However, there remains a wide dispersion in the incidence of unemployment amongst different sections of the community. In particular, compared with the general population, youth, Maori, Pacific Island's people and those people with low levels of educational attainment experience considerably higher rates of unemployment. As a result, although consensus forecasts suggest that labour market conditions are likely to further improve over coming years, continued substantial declines in aggregate unemployment will heavily depend on the labour market performance of these disadvantaged groups.

\section{Future research}

During late 1993, and through most of 1994, the Labour Market Analysis unit (LMA) conducted a major programme of research in support of the Prime Ministerial Task Force on Employment. This research included papers describing the characteristics of the New Zealand labour market, and reviewing the theory and empirical research underpinning various aspects of international labour market policy. The four LMA papers published in these proceedings are just a small sample of this research.

During 1995 this research will be extended in number of areas. For example, in response to the recommendations of the Employment Task Force, there will be considerable resources devoted to research on Maori labour market disadvantage. In addition, there will be further research aimed at identifying the characteristics of the long-term unemployed.

A sample of other projects planned include an analysis of wage dispersion and wage determination; an analysis of skills and skill mismatch; and research on labour force participation.

\section{Author}

Darren Gibbs is a Labour Market Advisor in the Labour Market Analysis Unit of the Department of Labour, PO Box 3705, Wellington. 